Analisis Faktor yang Mempengaruhi Kesiapan Pembelajaran Praktik Klinik Pertama Mahasiswa STIKes Panti Rapih Prodi Diploma Tiga Keperawatan Yogyakarta

\title{
ANALISIS FAKTOR YANG MEMPENGARUHI KESIAPAN \\ PEMBELAJARAN PRAKTIK KLINIK PERTAMA MAHASISWA \\ STIKES PANTI RAPIH PRODI DIPLOMA TIGA KEPERAWATAN \\ YOGYAKARTA
}

\author{
Bernadetta Eka Noviati ${ }^{1}$, Dwi Antara Nugraha ${ }^{2}$ \\ 1,STIKes Panti Rapih Yogyakarta, eka.vie@gmail.com \\ ${ }^{2}$ STIKes Panti Rapih Yogyakarta, raenantatiaraputri@gmail.com
}

\begin{abstract}
ABSTRAK
Latar Belakang: Pembelajaran praktik klinik di rumah sakit merupakan salah satu metode pembelajaran yang digunakan untuk mencetak praktisi perawat yang kompeten. Mahasiswa yang pertama kali menjalani pembelajaran klinik memiliki tingkat kesiapan yang berbeda-beda antara yang satu dengan yang lainnya.
\end{abstract}

Tujuan: Penelitian ini bertujuan mengidentifikasi dan menganalisis faktor-faktor yang mempengaruhi kesiapan mahasiswa STIKes Panti Rapih mengikuti pembelajaran praktik klinik keperawatan yang pertama.

Metode: Penelitian merupakan penelitian kuantitatif survey analitik dengan menggunakan pendekatan cross sectional. Populasi pada penelitian adalah mahasiswa Prodi Diploma Tiga Keperawatan STIKes Panti Rapih Yogyakarta. Sampel dalam penelitian adalah semua mahasiswa semester dua Prodi Diploma Tiga Keperawatan STIKes Pati Rapih Yogyakarta yang tercatat masih aktif dan memenuhi persyaratan untuk mengikuti praktik klinik keperawatan. Instrumen penelitian disusun dan dikembangkan oleh peneliti dan telah melalui uji validitas dan reliabilitas dengan hasil semua alat ukur valid dan reliable.

Hasil: Kesiapan fisik mahasiswa dalam pembelajaran praktik klinik keperawatan yang pertama terbanyak adalah kesiapan sedang dengan 59 responden $(60.8 \%)$. Kesiapan mental psikologis mahasiswa dalam mengikuti pembelajaran praktik klinik keperawatan yang pertama yang menyatakan siap sebanyak 54 responden $(55.7 \%)$. Kesiapan materiil mahasiswa dalam mengikuti pembelajaran praktik klinik keperawatan yang pertama 97 responden (100\%) menyatakan siap. Terdapat korelasi antara persiapan fisik dengan dengan kesiapan mentalpsikologis dengan korelasi rendah dengan nilai Correlation Coefficient sebesar 0.273 dan nilai signifikansi $p=0,007$. Terdapat korelasi minimal antara persiapan fisik dengan kesiapan materiil dengan nilai Correlation Coefficient sebesar 0.137 dan nilai signifikansi $p=0,187$. Tidak ada korelasi antara persiapan mental psikologis dengan kesiapan materiil dengan nilai Correlation Coefficient sebesar 0.142 dan nilai signifikansi $p=0,165$. Terdapat korelasi antara usia dengan dengan 
kesiapan mental-psikologis dengan tingkat korelasi rendah dengan nilai Correlation Coefficient sebesar 0.302 dan nilai signifikansi $p=0,00$.

Simpulan: Data penelitian tentang kesiapan fisik, kesiapan mental psikologis dan kesiapan materiil menunjukkan bahwa lebih 50\% responden siap. Hasil analisis menunjukkan bahwa faktor yang mempengaruhi mahasiswa dalam mengikuti pembelajaran praktik klinik keperawatan yang pertama adalah usia dengan nilai $p=0,003$ kemudian persiapan fisik dengan nilai $p=0,007$.

Kata kunci: kesiapan, pembelajaran klinik, mahasiswa

\begin{abstract}
Background: Learning clinical practice in a hospital is one of the learning methods used to provide competent nurse assistance. Students who first underwent clinical learning has a level of preparedness that different from each other.

Objective: This study aims to identify and analyze the factors that influence the readiness of School of Health Sciences Panti Rapih students to take part in learning the first practice of clinical nursing.

Methods: The research was a quantitative analytic survey research using cross sectional approach. The population in the study were students of Nursing Diploma Study Program in School of Health Sciences Panti Rapih Yogyakarta. The sample in this study were all second semester students of Nursing Diploma Study Program at School of Health Sciences Panti Rapih Yogyakarta, who were still active and fulfilled the requirements to attend nursing clinical practice. The research instruments was prepared and developed by researchers and have been tested for validity and reliability with the results of all valid and reliable measuring tools.

Results: The first physical readiness of students in learning clinical nursing practice was moderate readiness with 59 respondents (60.8\%). Mental psychological readiness of students in attending the first clinical nursing practice learning that states ready as many as 54 respondents $(55.7 \%)$. Material readiness of students in attending nursing clinical practice learning the first 97 respondents $(100 \%)$ said they were ready. There is a correlation between physical preparation with mental-psychological readiness with low correlation with a Correlation Coefficient value of 0.273 and a significance value of $p=0.007$. There is a minimum correlation between physical preparation and material readiness with a Correlation Coefficient of 0.137 and a significance value of $p=0.187$. There is no
\end{abstract}


correlation between mental psychological preparation with material readiness with a Correlation Coefficient value of 0.142 and a significance value of $p=0.165$. There is a correlation between age and mental-psychological readiness with a low correlation level with a Correlation Coefficient of 0.302 and a significance value of $\mathrm{p}=0.003$.

Conclusion: Research data on physical readiness, psychological mental readiness and material readiness show that more than $50 \%$ of respondents are ready. The results of the analysis show that the first factor influencing students in learning clinical nursing practice is age with a value of $\mathrm{p}=0.003$ then physical preparation with a value of $p=0.007$.

Keywords: readiness, clinical learning, students

\section{PENDAHULUAN}

Belajar adalah proses perubahan struktur mental individu yang dilakukan hingga seseorang yang belajar mampu menujukkan perubahan perilaku (Khadijah, 2011). Belajar merupakan suatu proses yang didalam diri pribadi seseorang, yang kemudian menimbulkan suatu pola baru berupa kecakapan, sikap, kepribadian, kepandaian dan suatu pengertian yang baru (Purwanto, 2010). Sudah sewajarnya, dengan belajar dapat mempengaruhi perubahan baik dari sisi pengetahuan, ketrampilan, dan sikap seorang individu.
Individu dapat mencerna dan mempelajari dengan lebih mudah karena telah memiliki kematangan yang cukup untuk menerima pembelajaran tersebut. Individu yang telah matang tersebut berarti telah memiliki kesiapan "readiness" dalam belajar. Dalam melaksanakan proses pembelajaran kesiapan merupakan kesediaan untuk memberi respon atau bereaksi (Slameto, 2013). Penguasaan ilmu pengetahuan, kompetensi, dan teknologi merupakan tuntutan global akan mutu lulusan pendidikan program diploma tiga keperawatan dan sistem pendidikan tinggi saat ini. Tuntutan akan kompetensi tersebut 
akan dapat diwujudnyatakan apabila peserta didik dapat mengikuti serangkaian pembelajaran yang efektif, inovatif dan berorientasi pada peserta didik (Sanjaya, 2016). Peserta didik dituntut untuk dapat belajar secara aktif, inovatif, dan mandiri dalam proses belajar.

Sementara itu institusi pendidikan diharapkan terus dapat meningkatkan perannya dalam menciptakan lingkungan belajar yang nyaman dan metode pembelajaran yang efektif. Dengan demikian institusi dapat memfasilitasi dan meningkatkan motivasi bagi mahasiswa sehingga diharapkan mahasiswa mampu mencapai kompetensi pembelajaran yang telah ditentukan (Muntamah, 2017).

Pelaksanaan pembelajaran adalah suatu kegiatan yang bernilai edukatif, dengan langkah-langkah yang diatur sedemikian rupa sehingga diharapkan mampu mencapai hasil seperti yang telah direncaanakan (Sujana, 2016). Praktik klinik di rumah sakit merupakan kurikulum wajib yang harus dijalani oleh setiap mahasiswa vokasional keperawatan dimanapun.
Kewajiban praktik klinik ini bertujuan untuk mempersiapkan mahasiswa program diploma keperawatan menjadi praktisi perawat vokasi yang kompeten di tempat kerjanya.

Pembelajaran klinik merupakan salah satu metode pembelajaran dimana memiliki tujuan untuk mendidik mahasiswa di klinik yang memungkinkan dosen/pembimbing klinik untuk memilih dan menerapkan cara mendidik yang sesuai dengan tujuan dan karakteristik individual mahasiswa berdasarkan kerangka konsep pembelajaran (Nursalam, 2008). Proses pembelajaran ini dipengaruhi baik oleh dosen maupun mahasiswa (Nurhidayah, 2011).

Pembelajaran

klinik merupakan proses bagi mahasiswa untuk mendapatkan kesempatan beradaptasi dalam melaksanakan praktik keperawatan profesional pada tatanan pelayanan kesehatan baik klinik maupun komunitas (Nursalam, 2015). Pembelajaran klinik memberikan andil besar terhadap kualitas lulusan perawat (Priyanti, Ratna, \& Nahariani, 2016). 
Berdasarkan wawancara langsung yang dilakukan oleh peneliti dengan beberapa CI Rumah Sakit (RS Panti Rapih: Lukas 3, RS Panti Rini: IGD) yang dilakukan pada saat proses pembelajaran klinik tahun sebelumnya dimana mahasiswa dipraktikkan, disampaiakan bahwa permasalahan yang sering ditemukan pada pembelajaran praktik klinik keperawatan adalah mahasiswa belum memiliki kemampuan aplikatif yang cukup.

Observasi dan anamnese yang dilakukan oleh pembimbing klinik Rumah Sakit dan Pendidikan terhadap mahasiswa pada tingkat yang sama beberapa tahun ke belakang menemukan bahwa lebih dari separo mahasiswa tingkat dua yang melaksanakan praktik klinik di rumah sakit masih kebingungan, belum memahami apa yang harus dilakukan, dan belum cukup memiliki kepercayaan diri untuk memberikan asuhan langsung kepada pasien.

Fenomena tersebut menjadi satu pertanyaan bagi pembimbing pendidikan, dan juga pembimbing
RS, karena sebelum mahasiswa praktik klinik mahasiswa telah dibekali dengan teori (dikelas) dan ketrampilan (praktik laboratorium) namun mengapa hal tersebut tetap terjadi. Untuk dapat menjawab secara ilmiah mengenai fenomena yang terjadi, maka peneliti akan melakukan penelitian dengan judul, "Analisis Faktor yang Mempengaruhi Kesiapan Pembelajaran Praktik Klinik Keperawatan Pertama Mahasiswa STIKes Panti Rapih Prodi Diploma Tiga Keperawatan Yogyakarta”.

\section{METODE PENELITIAN}

Penelitian ini merupakan penelitian survey analitik dengan menggunakan pendekatan cross sectional. Artinya bahwa, tiap subyek penelitian hanya diobservasi sekali saja dan pengukuran dilakukan terhadap status karakter atau variabel subjek pada saat pemeriksaan. Hal ini tidak berarti bahwa semua subjek penelitian diamati pada waktu yang sama. Subyek penelitian ini adalah mahasiswa STIKes Panti Rapih Yogyakarta Prodi Diploma Tiga 
Keperawatan angkatan 2016/2017 semester dua yang tercatat masih aktif dan memenuhi persyaratan untuk mengikuti praktik klinik keperawatan.

Instrumen pada penelitian ini disusun dan dikembangkan oleh peneliti dan sudah melalui uji validitas dengan hasil 0.32-0.99 (> dari $r$ tabel 0.31) yang berarti instrumen telah valid dan tes reliabilitas dengan hasil 0.5240 . Dengan demikian saat instrumen dipakai telah memiliki nilai valid dan reliable.

\section{Analisis data dilakukan} dengan analisis univariat untuk mengetahui karakteristik responden. Analisis data ini bertujuan untuk uji statistik yang meliputi statistik parametrik (untuk data interval dan rasio) dan non parametrik (untuk data nominal dan ordinal). Penggunaan satistik parametrik mensyaratkan bahwa data setiap variabel yang akan dianalisis harus berdistribusi normal. Uji normalitas data menggunakan uji KolmogorovSmirnov dengan hasil Sig 2-tiled 0.000 yang artinya data tidak berdistribusi normal.

\section{HASIL DAN PEMBAHASAN}

\section{Karakteristik Responden}

Tabel 1

Karakteristik responden $(\mathrm{n}=97)$

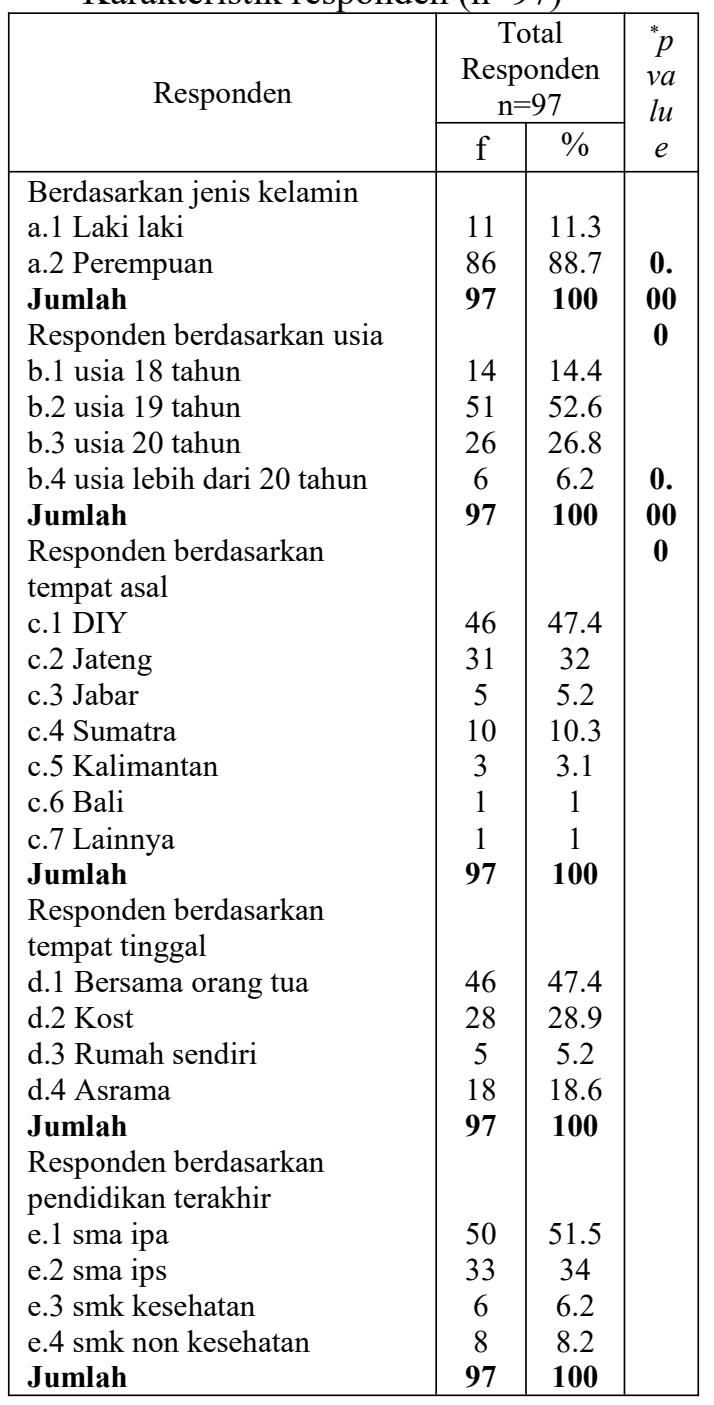

Sumber: data primer

Uji homogenitas jenis kelamin dan usia menggunakan uji KS hasilnya Sig 2 tild 0.000 (lebih kecil dari $\mathrm{p}$ value 0.05 ), dengan demikian maka data ini tidak homogen, maka analisis selanjutnya menggunakan analisis korelasi non-parametrik. 
Analisis Faktor yang Mempengaruhi Kesiapan Pembelajaran Praktik Klinik Pertama Mahasiswa STIKes Panti Rapih Prodi Diploma Tiga Keperawatan Yogyakarta

Data penelitian yang ditunjukkan pada tabel 1 tentang jenis kelamin adalah 86 responden (86.7\%) merupakan responden wanita, sedangkan 11 responden (11.3\%) adalah responden laki-laki. Dominasi wanita pada institusi kesehatan khususnya perawat, sangat lazim terjadi. Tidak ada alasan khusus terkait dengan hal tersebut, hanya diduga bahwa hal tersebut berkaitan dengan fleksibilitas dalam melaksanakan tugas dan tanggung jawabnya. Dominasi jumlah wanita lebih banyak pada profesi keperawatan sesuai dengan sebaran mahasiswa berdasarkan jenis kelamin yang belajar di STIKes Panti Rapih. Penelitian ini sejalan dengan penelitian yang dilakukan oleh Anisa, Suryani, \& Mirwanti (2018), tentang tingkat kecemasan mahasiswa keperawatan dalam menghadapi ujian berbasis computer base test yang menyebutkan bahwa jumlah mahasiswa perawat didominasi oleh wanita.

Usia mahasiswa tingkat dua didominasi pada usia 19 tahun sebanyak 51 reaponden $(52,6 \%)$. Hal ini menjadi sebuah kewajaran karena usia memulai sekolah dasar di Indonesia adalah 6 tahun (Mendikbud, 2018). Dengan demikian menjadi wajar apabila mahasiswa tingkat dua didominasi pada usia 19 tahun (Mendikbud RI, 2018).

Distribusi frekuensi tempat asal didominasi oleh responden yang berasal dari DIY sebanyak 46 responden (47.4\%), Jateng 31 responden (32\%), Sumatra 10 responden (10.3\%), Jabar 5 responden (5.2\%), Bali 1 responden (1\%), lainnya 1 responden (1\%).

Distribusi frekuensi responden berdasarkan tempat tinggal yang ditunjukkan oleh tabel 1 terdapat 46 responden (47.4\%) tinggal bersama orang tua, 28 responden (28.9\%) tinggal dengan status kost, 18 responden (18.6\%) tinggal di asrama dan 5 responden $(5.2 \%)$ berstatus tinggal di rumah sendiri.

Pendidikan terakhir dari responden yang ditunjukkan oleh tabel 1 adalah 50 responden (51.5\%) dengan pendiidkan terakhir SMA dengan jurusan IPA, 33 responden (34\%) dengan pendidikan terakhir SMA dengan jurusan IPS, 8 
responden $(8.2 \%)$ dengan pendidikan terakhir SMK non kesehatan dan 6 responden $(6.2 \%)$ dengan pendidikan terakhir SMK kesehatan.

Tabel 2

Kesiapan mahasiswa dalam menghadapi pembelajaran klinik pertama

\begin{tabular}{|c|c|c|c|c|c|c|}
\hline \multirow{2}{*}{$\begin{array}{c}\text { Kesiapan } \\
\text { mahasiswa } \\
\text { dalam } \\
\text { menghadapi } \\
\text { praktik } \\
\text { klinik } \\
\text { pertama } \\
\end{array}$} & \multicolumn{2}{|c|}{ Fisik } & \multicolumn{2}{|c|}{$\begin{array}{l}\text { Mental- } \\
\text { Psikolo } \\
\text { gis }\end{array}$} & \multicolumn{2}{|c|}{ Materiil } \\
\hline & $\mathrm{n}$ & $\%$ & $\mathrm{n}$ & $\%$ & $\mathrm{n}$ & $\%$ \\
\hline $\begin{array}{l}\text { 1. Kesiapan } \\
\text { dinilai } \\
\text { kurang }\end{array}$ & 21 & 21.6 & 3 & 3.1 & 0 & 0 \\
\hline $\begin{array}{l}\text { 2. Kesiapan } \\
\text { dinilai } \\
\text { sedang }\end{array}$ & 59 & 60.8 & 40 & 41.2 & 0 & 0 \\
\hline $\begin{array}{l}\text { 3. Kesiapan } \\
\text { dinilai sian }\end{array}$ & 17 & 17.5 & 54 & 55.7 & 97 & 100 \\
\hline $\begin{array}{l}\Sigma \\
\text { responden }\end{array}$ & 97 & 100 & 97 & 100 & 97 & 100 \\
\hline
\end{tabular}

Sumber: data primer

Kesiapan aspek fisik yang menunjukkan kesiapan sedang adalah 59 responden (60.8\%), kurang siap 21 responden $(21.6 \%)$ dan yang menyatakan siap 17 responden (15.5\%). Kesiapan mental-psikologis siap dinyatakan oleh 54 responden (55.7\%), kesiapan sedang 40 responden $(41.2 \%)$ dan tidak siap 3 responden $\quad(3.1 \%)$. Sedangkan kesiapan dari sisi materiil meyatakan $100 \%$ siap.

Tiga aspek yang mempengaruhi kesiapan didalam proses pembelajaran ini, dirasakan oleh setiap mahasiswa. Apalagi proses pembelajaran yang sedang dijalani adalah praktik klinik keperawatan di rumah sakit, dimana mahasiswa harus mengalami kontak pertama kali dengan pasien secara senyatanya. Dengan kemampuan untuk mempersiapkan kondisikondisi tertentu yang mendahului proses pembelajaran bagi mahasiswa, diharapkan proses belajar tersebut dapat terjadi dan berjalan dengan baik (Nasution, 2011).

Kesiapan materiil responden dalam persiapan pembelajaran praktik klinik $100 \%$ siap, artinya adalah bahwa mahasiswa merasa siap terhadap apa yang akan dipraktikkan, mahasiswa mempersiapkan diri dengan belajar, mengikuti pembelajaran laboratorium praktik, mahasiswa merasa siap dengan buku penunjang pembelajaran praktik klinik sebagai literature ilmiah, juga telah memiliki nursing kid. Hal ini sesuai dengan yang diungkapkan oleh (Daldiyono, 2015), bahwa salah satu faktor yang mempengaruhi pembelajaran adalah faktor perlengkapan belajar. 
Analisis Faktor yang Mempengaruhi Kesiapan Pembelajaran Praktik Klinik Pertama Mahasiswa STIKes Panti Rapih Prodi Diploma Tiga Keperawatan Yogyakarta

Perlengkapan belajar yang disebutkan termasuk diantaranya adalah perlengkapan materiil.

Tabel 3

Korelasi antara kesiapan fisik dengan kesiapan mental psikologis mahasiswa dalam pembelajaran klinik

\begin{tabular}{|c|c|c|c|c|c|c|}
\hline \multirow{2}{*}{$\begin{array}{l}\text { Kesiapan } \\
\text { mahasiswa } \\
\text { dalam } \\
\text { menghadapi } \\
\text { praktik } \\
\text { klinik } \\
\text { pertama }\end{array}$} & \multicolumn{2}{|c|}{$\begin{array}{l}\text { Kesiapan } \\
\text { Fisik }\end{array}$} & \multicolumn{2}{|c|}{$\begin{array}{l}\text { Kesiap } \\
\text { an } \\
\text { Mental- } \\
\text { Psikolo } \\
\text { gis }\end{array}$} & \multirow[t]{2}{*}{$p$} & \multirow[t]{2}{*}{$\begin{array}{l}\text { Cor } \\
\text { rela } \\
\text { tion } \\
\text { Coe } \\
\text { ffici } \\
\text { ent }\end{array}$} \\
\hline & $\mathrm{n}$ & $\%$ & $\mathrm{n}$ & $\%$ & & \\
\hline $\begin{array}{l}\text { 1. Kesiapan } \\
\text { dinilai } \\
\text { kurang }\end{array}$ & 21 & 21.6 & 3 & 3.1 & & \\
\hline $\begin{array}{l}\text { 2. Kesiapan } \\
\text { dinilai } \\
\text { cukup }\end{array}$ & 59 & 60.8 & 40 & $\begin{array}{c}41 . \\
2\end{array}$ & $\begin{array}{l}0 . \\
00\end{array}$ & 0.2 \\
\hline $\begin{array}{l}\text { 3. Kesiapan } \\
\text { dinilai } \\
\text { siap }\end{array}$ & 17 & 17.5 & 54 & $\begin{array}{c}55 . \\
7\end{array}$ & 7 & 73 \\
\hline $\begin{array}{l}\text { Jumlah } \\
\text { responden }\end{array}$ & 97 & 100 & 97 & 100 & & \\
\hline
\end{tabular}

Sumber: data primer

Nilai signifikansi korelasi antara kesiapan fisik dengan kesiapan mental psikologis mahasiswa dalam pembelajaran klinik sebesar $p=0,007$, yang berarti, terdapat korelasi antara persiapan fisik dengan kesiapan mentalpsikologis dengan tingkat korelasi rendah yang ditunjukkan dengan nilai Correlation Coefficient sebesar 0.273 .

Kesiapan fisik pada mahasiswa yang mengikuti pembelajaran sering kali membawa pengaruh ke kesiapan psikologis.
Mahasiswa yang mengalami kelelahan secara fisik, mengakibatkan secara psikologis menjadi kurang siap dalam menghadapi pembelajaran. Mahasiswa yang secara fisik tidak siap, dapat menimbulkan kecemasan dalam proses belajar. Hal ini sesuai dengan Rizka \& Rochanawati, (2015) bahwa ada hubungan antara kesiapan dengan tingkat kecemasan menghadapi real teaching pada mahasiswa.

Tabel 4

Korelasi antara kesiapan fisik dengan kesiapan materiil mahasiswa dalam pembelajaran klinik

\begin{tabular}{|c|c|c|c|c|c|c|}
\hline \multirow{2}{*}{$\begin{array}{c}\text { Kesiapan } \\
\text { mahasiswa } \\
\text { dalam meng } \\
\text { hadapi praktik } \\
\text { klinik } \\
\text { pertama } \\
\end{array}$} & \multicolumn{2}{|c|}{$\begin{array}{c}\text { Kesiapan } \\
\text { Fisik } \\
\end{array}$} & \multicolumn{2}{|c|}{$\begin{array}{c}\text { Kesiapan } \\
\text { Materiil }\end{array}$} & \multirow[b]{2}{*}{$p$} & \multirow{2}{*}{$\begin{array}{l}\text { Cor } \\
\text { rela } \\
\text { tion } \\
\text { Coe } \\
\text { ffici } \\
\text { ent }\end{array}$} \\
\hline & $\mathrm{n}$ & $\%$ & $\mathrm{n}$ & $\%$ & & \\
\hline $\begin{array}{l}\text { 1. Kesiapan } \\
\text { dinilai } \\
\text { kurang }\end{array}$ & 21 & 21.6 & 0 & 0 & & \\
\hline $\begin{array}{l}\text { 2. Kesiapan } \\
\text { dinilai cukup }\end{array}$ & 59 & 60.8 & 0 & 0 & 0.1 & $\begin{array}{l}0.1 \\
37\end{array}$ \\
\hline $\begin{array}{l}\text { 3. Kesiapan } \\
\text { dinilai } \\
\text { siap }\end{array}$ & 17 & 17.5 & 97 & 100 & 81 & 3 \\
\hline$\Sigma$ Responden & 97 & 100 & 97 & 100 & & \\
\hline
\end{tabular}

Sumber: data primer

Nilai signifikansi sebesar $p=0,187$, hampir tidak ada korelasi antara persiapan fisik dengan kesiapan materiil yang ditunjukkan dengan nilai Correlation Coefficient sebesar 0.137. Mahasiswa yang siap secara fisik tidak berkaitan langsung 
dengan kesiaap materiil yang dimiliki. Mahasiswa akan melakukan pembelajaran secara optimal dengan kondisi fisik yang baik ditambah dengan kondisi materiil yang baik. Djamarah, Bahri, \& Aswan (2013) mengemukakan bahwa kesiapan belajar merupakan kondisi diri yang telah mempersiapkan diri untuk melakukan suatu kegiatan. Kondisi tersebut meliputi kondisi fisik, dan mental dari individu yang akan melakukan proses pembelajaran.

Tabel 5

Korelasi antara kesiapan mental psikologis dengan kesiapan materiil mahasiswa semester 3 dalam pembelajaran klinik

\begin{tabular}{|c|c|c|c|c|c|c|}
\hline \multirow{2}{*}{$\begin{array}{c}\text { Kesiapan } \\
\text { mahasiswa } \\
\text { dalam } \\
\text { menghadapi } \\
\text { praktik } \\
\text { klinik } \\
\text { pertama }\end{array}$} & \multicolumn{2}{|c|}{$\begin{array}{c}\text { Kesiapan } \\
\text { Mental } \\
\text { Psikologis }\end{array}$} & \multicolumn{2}{|c|}{$\begin{array}{c}\text { Kesiapan } \\
\text { Materiil }\end{array}$} & \multirow{2}{*}{$p$} & \multirow{2}{*}{$\begin{array}{l}\text { Co } \\
\text { rre } \\
\text { lat } \\
\text { ion } \\
\text { Co } \\
\text { effi } \\
\text { cie } \\
\text { nt }\end{array}$} \\
\hline & $\mathrm{n}$ & $\%$ & $\mathrm{~N}$ & $\%$ & & \\
\hline $\begin{array}{l}\text { 1. Kesiapan } \\
\text { dinilai }\end{array}$ & 3 & 3.1 & 0 & 0 & & \\
\hline $\begin{array}{l}\text { Kurang } \\
\text { 2. Kesiapan } \\
\text { dinilai } \\
\text { cukup }\end{array}$ & 40 & 41.2 & 0 & 0 & & 0.1 \\
\hline $\begin{array}{l}\text { 3. Kesiapan } \\
\text { dinilai } \\
\text { siap }\end{array}$ & 54 & 55.7 & 97 & 100 & $\begin{array}{c}10 \\
5\end{array}$ & 42 \\
\hline $\begin{array}{l}\text { Jumlah } \\
\text { responden }\end{array}$ & 97 & 100 & 97 & 100 & & \\
\hline
\end{tabular}

Sumber: data primer

Nilai signifikansi sebesar $p=0,165$, tidak ada korelasi antara persiapan mental psikologis dengan kesiapan materiil, ditunjukkan dengan nilai Correlation Coefficient sebesar 0.142. Dengan data yang diperoleh, tidak ada keterkaitan antara kepemilikan materiil penunjang pembelajaran yang dimiliki dengan kesiapan dari faktor psikologis. Bahwa mahasiswa yang belum siap secara psikologis dalam menghadapi pembelajaran klinik, tidak akan menjadi merasa lebih siap hanya dengan memiliki materiil pendukung pembelajaran. Hal ini sesuai yang diungkapkan Daldiyono (2015), bahwa kesiapan belajar merupakan keadaan seseorang untuk mempersiapkan diri baik secara fisik, mental, maupun perlengkapan belajar.

Tabel 6

Korelasi antara usia dengan kesiapan mental psikologis dalam persiapan pembelajaran klinik

\begin{tabular}{|c|c|c|c|c|}
\hline \multirow{2}{*}{ Variabel } & \multicolumn{2}{|c|}{$\begin{array}{c}\text { Responden } \\
\mathrm{n}=97\end{array}$} & \multirow{2}{*}{$* p$} & \multirow{2}{*}{$\begin{array}{c}\text { Corre } \\
\text { lation } \\
\text { Coeffi } \\
\text { cient }\end{array}$} \\
\hline & $\mathrm{n}$ & $\%$ & & \\
\hline Usia & & & & \\
\hline 18 tahun & 14 & 14.4 & & \\
\hline 19 tahun & 51 & 52.6 & & \\
\hline 20 tahun & 26 & 26.8 & & \\
\hline $\begin{array}{l}\text { lebih dari } 20 \\
\text { tahun }\end{array}$ & 6 & 6.2 & & \\
\hline Jumlah & 97 & 100 & & \\
\hline Kesiapan Mental- & & & 0.0 & \\
\hline Psikologis & & & 03 & 0.302 \\
\hline $\begin{array}{l}\text { 1. Kesiapan } \\
\text { dinilai kurang }\end{array}$ & 3 & 3.1 & & \\
\hline $\begin{array}{l}\text { 2. Kesiapan } \\
\text { dinilai cukup }\end{array}$ & 40 & 41.2 & & \\
\hline $\begin{array}{l}\text { 3. Kesiapan } \\
\text { dinilai siap }\end{array}$ & 54 & 55.7 & & \\
\hline $\begin{array}{l}\text { Jumlah } \\
\text { responden }\end{array}$ & 97 & 100 & & \\
\hline
\end{tabular}

Sumber: data primer 
Analisis Faktor yang Mempengaruhi Kesiapan Pembelajaran Praktik Klinik Pertama Mahasiswa STIKes Panti Rapih Prodi Diploma Tiga Keperawatan Yogyakarta

Nilai signifikansi sebesar $p=0,003$, terdapat korelasi antara usia dengan dengan kesiapan mentalpsikologis dengan tingkat korelasi rendah yang ditunjukkan dengan nilai Correlation Coefficient sebesar 0.302. Semakin usia bertambah dewasa maka secara fisiologis kematangan mental psikologis semakin bertambah pula, semakin matang usia semakin siap mahasiswa keperawatan diploma tiga semester tiga dalam menghadapi pembelajaran klinik. Hal ini tidak didukung oleh Syarfina, Arsyad, \& Zalika 2018), faktor-faktor yang berhubungan dengan kesiapan belajar mandiri pada mahasiswa angkatan 2015 dan angkatan 2013 diantaranya adalah kepercayaan dlri, gaya belajar, motlvasi belajar, sumber belajar dan waktu belajar.

\section{KESIMPULAN DAN SARAN}

\section{Kesimpulan}

Faktor yang mempengaruhi
kesiapan pembelajaran klinik
pertama kali bagi mahasiswa adalah
faktor kesiapan fisik, kesiapan
psikologis dan kesiapan materiil.

Kesiapan fisik manyatakan siap pada 17.5\% mahasiswa, kesiapan cukup untuk $60,8 \%$ mahasiswa. Faktor kesiapan psikologis dinilai cukup pada 49,2\% mahasiswa dan dinilai siap pada 55,7\%. Sedangkan kesiapan materiil didapatkan 100\% mahasiswa siap secara materiil. Hampir tidak ada korelasi sebesar 0.181 antara kesiapan fisik dengan kesiapan materiil mahasiswa dalam pembelajaran klinik dengan nilai Correlation Coefficient 0,131 . Korelasi tidak berarti antara kesiapan mental psilogis dengan kesiapan materiil mahasiswa semester 3 dalam pembelajaran klinik ditunjukkan dengan nilai significansi $p=0,165$ dari nilai Correlation Coefficient 0.142. Korelasi cukup kuat dengan nilai $\mathrm{p}=0,003$ antara usia dengan kesiapan mental psilogis dalam persiapan pembelajaran klinik dengan nilai Correlation Coefficient sebesar 0.302 .

\section{Saran}

Bagi peneliti lain untuk mengembangkan penelitian tentang kesiapan pembelajaran klinik dengan 
mengembangkan metode yang lain hingga mendapatkan hasil yang lebih mendalam. Juga dapat dikembangkan meninjau kesiapan pembelajaran klinik dari aspek yang lain seperti pembimbing, pengajar, dan CI (Clinical Instructure).

\section{DAFTAR PUSTAKA}

Anisa, L. M., Suryani, \& Mirwanti, R. (2018). Tingkat Kecemasan Mahasiswa Keperawatan Dalam Menghadapi Ujian Berbasis Computer Based Test. Medisain Jurnal Ilmiah IlmuIlmu Kesehatan, 16(2), 67-75.

Daldiyono. (2015). Psikologi Pendidikan . Jakarta: Rineka Cipta.

Djamarah, Bahri, S., \& Aswan, Z. (2013). Strategi Belajar. Jakarta: Rineka Cipta.

Khadijah, N. (2011). Psikologi Belajar. Palembang: IAIN Raden Patah Press.

Mendikbud RI. (2018, Desember 31). Peraturan Menteri Pendidikan Dan Kebudayaan Republik Indonesia Nomor 51 Tahun 2018 tentang Penerimaan Peserta Didik baru pada Taman Kanak-Kanak, Sekolah Dasar, Sekolah Menengah Pertama, Sekolah Menengah Atas, dan Sekolah Menengah Kejuruan. Jakarta, Indonesia. Dipetik Desember
19, 2019, Dari Https://Jdih.Kemdikbud.Go.I $\mathrm{d} /$ Arsip/PERMENDIKBUD $\% 20$ NOMOR\%2051\%20TA HUN\%202018.Pdf

Muntamah, U. (2017). Analisis Pengaruh Metode Pembelajaran Praktik Laboratorium Berdasarkan Target Kompetensi Terhadap Peningkatan Skill Pada Mata Ajar Keperawatan Gawat Darurat Dan Manajemen Bencana. The 1steducation And Language International Conference Proceedings Center For International Language Development of Unissula, 880-888.

Nasution, S. (2011). Berbagai Pendekatan Dalam Proses Belajar Dan Mengajar. Jakarta: Penerbit Bumi Aksara.

Nurhidayah. (2011). Pendidikan Keperawatan. Pendekatan Kurikulum Berbasis Kompetensi. Medan: USU Press.

Nursalam. (2008). Pendidikan Dalam Keperawatan. Jakarta : Salemba Medika.

Nursalam. (2015). Manajemen Keperawatan Aplikasi Dalam Praktik Keperawatan Profesional. Edisi 5. . Jakarta: Penerbit Salemba Medika.

Priyanti, Ratna, P., \& Nahariani, P. (2016). Skala Evaluasi Lingkungan Belajar Klinik, Supervisi, dan Dosen Perawat 
Analisis Faktor yang Mempengaruhi Kesiapan Pembelajaran Praktik Klinik Pertama Mahasiswa STIKes Panti Rapih Prodi Diploma Tiga Keperawatan Yogyakarta

(Clinical Learning

Environmental, Supervision, And Nurse Teacher-Cles + T) Versi Bahasa Indonesia: Validitas Dan Reliabilitas. Jurnal Ilmiah Kesehatan. Volume 9. No.2, 107-113. .

Purwanto. (2010). Evaluasi Hasil Belajar. Yogyakarta: Pustaka Pelajar. Yogyakarta: Pustaka Pelajar.

Rizka, F., \& Rochanawati, D. (2015). Hubungan Kesiapan Dengan Tingkat Kecemasan Menghadapi Real Teaching Pada Mahasiswa DIV Bidan Pendidik Anvullen STIKES Aisyiyah Yogyakarta Tahun 2014 . Repositori, Unisa Digital Librari, Http://Digilib.Unisayogya.Ac. $\mathrm{Id} / \mathrm{Id} /$ Eprint/995.

Sanjaya, W. (2016). Pembelajaran Dalam Imlpementasi Kurikulum Berbasis Kompetensi. Jakarta: Kencana Renata Grup.
Slameto. (2013). Belajar Dan Faktor-Faktor Yang Mempengaruhinya. Jakarta: PT. Rineka Cipta. . Jakarta: PT. Rineka Cipta.

Sujana, N. (2016). Penilaian Hasil Proses Belajar Mengajar. Bandung: PT Remaja Rosdakarya Offset.

Syarfina, B., Arsyad, K., \& Zalika, P. (2018). Faktor-Faktor Yang Berhubungan Dengan Kesiapan Belajar Mandiri (Self Directed Learning Readiness) PADA Mahasiswa Angkatan 2015 Dan Angkatan 2013 Fakultas Kedokteran Universitas Muhammadiyah Palembang . Palermbang http://repository.umpalembang.ac.id/id/eprint/225 9. 